\title{
ESTRATÉGIAS DE ENFRENTAMENTO UTILIZADAS POR PROFESSORES DO ENSINO MÉDIO EM SITUAÇÃO DE ESTRESSE
}

\section{Couse strategies used by stress high school teachers}

\author{
Hiolly Cristina Lucena- UESPI/ Brasil \\ Camila Siqueira Cronemberger Freitas -UESPI/ Brasil
}

\begin{abstract}
RESUMO: O respectivo estudo tem o objetivo geral de investigar as estratégias de enfrentamento utilizadas por professores do ensino médio em situações de estresse, os objetivos específicos foram conhecer os fatores que estão causando situação de estresse, investigar as estratégias utilizadas pelos professores para enfrentar tais situações e analisar as implicações dessas situações estressoras no processo de ensino-aprendizagem. Trata-se de um estudo qualitativo, descritivo-exploratório. A amostra foi composta por 10 professores de uma escola pública estadual da cidade de Teresina no Piaú, para a coleta foi realizada um questionário sociodemográfico e entrevista-semiestruturada. Os dados apontaram que os professores usaram estratégias focalizadas no problema, como: parar e analisar a situação, falar baixo com os alunos, respirar fundo, dialogar, mudar os alunos de lugar e manter autoridade dentro de sala de aula, em busca de diminuir ou sanar com o fator estressor de forma mais rápida e as focalizadas na emoção, como: rezar, fazer exercícios físicos e ouvir música, para alterar o estado emocional procurando diminuir ou regular a sensação desagradável causada pelo estresse. Dessa forma, este estudo procura promover o conhecimento de como os professores podem se proteger desses fatores estressantes, auxiliando não somente o próprio sujeito, como também a sociedade de maneira geral, visto que esta profissão possui um valor enorme para o desenvolvimento de uma nação.
\end{abstract}

Palavras-chave: Enfrentamento. Estresse. Professores.

ABSTRACT: The main objective of this study was to investigate the coping strategies used by high school teachers in stressful situations, the specific objectives were to know the factors that are causing a stressful situation, investigating the strategies used by teachers to address such situations and analyze the implications of these stressful situations in the teaching-learning process. This is a qualitative, descriptive-exploratory study. The sample consisted of 10 teachers from a state public school in the city of Teresina in Piauí, for the collection, a sociodemographic and semi-structured interview questionnaire was performed. The data pointed out that teachers used strategies focused on the problem, such as: stopping and analyzing the situation, talking low with students, breathing deep, dialog, changing students and maintaining authority within the classroom, in order to slow down or remedy with the stressor factor faster and focused on emotion such as: praying, exercising and listening to music, to change the emotional state seeking to decrease or regulate the unpleasant feeling caused by stress. Thus, this study seeks to promote the knowledge of how teachers can protect themselves from these stressful factors, helping not only the subject himself, but also society in general, since this profession has a enormous value for the development of a nation.

Keywords: Coping. Stress. Teachers.

Educação, Psicologia e Interfaces, Volume 4, Número 2, p. 135-149, Abril/Junho, 2020.

ISSN: 2594-5343. DOI: $10.37444 /$ issn-2594-5343.v4i2.234 


\section{INTRODUÇÃO}

Segundo pesquisa apresentada pela Organização Internacional do Trabalho - OIT em 2019 o estresse está entre uma das principais causas de mortes em cerca de quase 2,8 milhões de trabalhadores (ONU, 2019). Uma pesquisa realizada pelo instituto de Psicologia e Controle do Stress no Brasil em 2014 indicou que 34,26\% dos entrevistados apresentaram nível de estresse extremo, tendo a sobrecarga do trabalho como o terceiro maior fator estressor e 52,28\% apresentando que tiveram ou tem o diagnóstico de estresse (IPCS, 2014).

Santos e Vidal (2017) apontam que o estresse na atualidade é um dos grandes problemas na saúde, sendo a classe dos trabalhadores professores constantemente atingida, este impacto nos docentes muitas vezes se reflete por conta da sua grande dedicação e o não reconhecimento da mesma trazendo pontos negativos a sua maneira de trabalhar e a sua saúde de modo geral, seja ela, física ou psíquica. Essa falta de reconhecimento é levantada por Tostes et al. (2018, p. 90):

A redução da importância do trabalho do professor na transmissão do conhecimento e a acentuação de seu papel na reprodução de uma força de trabalho flexível - apenas voltada à empregabilidade - esvaziam de significado o trabalho docente, influenciando negativamente sua saúde.

Segundo Lipp (2000 apud LIPP, 2016) o estresse é caracterizado como uma reação do organismo do sujeito, pelos aspectos físicos, psicológicos e hormonais, diante de um determinado acontecimento e que acomete sua estabilidade física ou mental.

À princípio, de acordo com Krawczyk (2011), na contemporaneidade exige-se professores com formação de êxito, que estejam motivados e atualizados, entretanto o sistema ao qual estão imersos é de danificação e extremo desamparo, tendo em vista que as condições de trabalho oferecidas são precárias, diante de um contexto em que há uma desqualificação do professor e instabilidade financeira, além de escolas com estrutura física que não oferece nenhum suporte ao professor, ou seja, um cenário de trabalho caótico e que prejudica o seu bem estar.

Assim como apresentado por Bittencourt et al. (2010), foi na década de noventa que o estresse foi considerado pela Organização Mundial da Saúde (OMS) como uma epidemia mundial. Devido às diversas variáveis externas e internas que contribuem para o crescimento desta epidemia conhecida como o mal do século, os professores precisam

Educação, Psicologia e Interfaces, Volume 4, Número 2, p. 135-149, Abril/Junho, 2020. 
ter conhecimento de como lidar com isso, visto que é uma das classes trabalhadoras mais atingidas segundo a literatura.

Diante disso, o presente estudo partiu da seguinte problemática: Quais as estratégias de enfrentamento utilizadas pelos professores do ensino médio em situação de estresse? Por meio disso teve como objetivo geral investigar as estratégias de enfrentamento utilizadas pelos professores de ensino médio em situações de estresse, e para isso buscou-se conhecer os fatores que estão causando situações de estresse nos professores de ensino médio, investigar as estratégias utilizadas pelos professores para enfrentar tais situações e analisar as implicações dessas situações estressoras no processo de ensino-aprendizagem.

Dessa forma este estudo procura promover o conhecimento de como os professores podem se proteger desses fatores estressantes, auxiliando não somente o próprio sujeito, como também a sociedade de maneira geral, visto que esta profissão possui um valor enorme para o desenvolvimento de uma nação.

\section{MATÉRIAL E MÉTODO}

O estudo caracteriza-se como uma pesquisa de abordagem qualitativa, descritivaexploratória. A pesquisa qualitativa se preocupa com o aprofundamento da compreensão e a dinâmica de um determinado grupo social, busca descrever, compreender e explicar a precisão das relações entre global e o local em determinado fenômeno, que não podem ser reduzidos à operacionalização de variáveis (GERHARDT; SILVEIRA, 2009, MINAYO, 2002).

Quanto aos objetivos, é classificada como pesquisa exploratória e descritiva. De acordo com Gil (2002), a pesquisa exploratória busca familiarizar-se com o problema a ser investigado e aprimoramento de ideias, além de ser flexível, visto que considera aspectos relativos ao objeto estudado; já a pesquisa descritiva busca a informação e a descrição das características do fenômeno.

\subsection{Participantes e local}

A amostra foi composta por 10 professores de uma escola pública estadual do município de Teresina - Piauí. Para atender os objetivos foram selecionados professores 
que se enquadrassem nos requisitos da amostra. Assim, os critérios de inclusão dos professores no estudo foram estar atuando na escola há pelo menos 1 (um) ano e que fosse professor do Ensino Médio.

\subsection{Instrumentos e coleta de dados}

Os dados foram coletados individualmente, tendo como instrumentos de dados para a coleta: um questionário sociodemográfico para serem coletados os dados pessoais e históricos acerca de experiências da vida profissional do participante e entrevista semiestruturada contendo um roteiro de 10 perguntas subdivididas em três blocos: bloco A - Fatores causadores de estresse nos professores; bloco B - Estratégias de enfrentamento de estresse; bloco C - O estresse e o processo de ensino aprendizagem. Os dados foram registrados por meio de um gravador, caneta, papel e notebook para transcrição. Quanto à seleção da amostra a ser pesquisada aconteceu através da técnica Snowball ou "Bola de Neve", que de acordo com Baldin e Munhoz (2011), consiste de uma amostra não probabilística, no qual os participantes com o perfil do fenômeno a ser pesquisado indicam outros sujeitos que se adaptam também a pesquisa.

\subsection{Análise dos dados}

A realização da análise dos dados coletados na pesquisa foi feita utilizando a Análise de Conteúdo de Laurence Bardin. Segundo a autora o método "é um conjunto de análise das comunicações. (...) marcado por uma grande disparidade de formas e adaptável a um campo de aplicação muito vasto: as comunicações” (BARDIN, 2016, p. 34). A etapa da organização do método é subdividida em três fases de análise dos conteúdos das mensagens: a pré-análise, a exploração do material e o tratamento dos resultados, com a inferência e interpretação (BARDIN, 2016).

\section{RESULTADOS E DISCUSSÕES}

Participaram do estudo 10 professores de uma escola pública estadual da cidade de Teresina- Piauí, de ambos os sexos. Caracterizados segundo os dados obtidos no questionário sociodemográfico abaixo, com as seguintes variáveis: gênero, idade, escolarização, disciplina ministrada e número de turmas.

Educação, Psicologia e Interfaces, Volume 4, Número 2, p. 135-149, Abril/Junho, 2020. 
Quadro 1 - Dados sociodemográficos dos professores

\begin{tabular}{|c|c|c|c|c|c|}
\hline PROFESSORES & GÊNERO & IDADE & ESCOLARIZAÇÃo & $\begin{array}{c}\text { DISCIPLINA } \\
\text { MINISTRADA }\end{array}$ & $\begin{array}{c}\text { N }^{\circ} \text { DE } \\
\text { TURMAS }\end{array}$ \\
\hline P1 & F & 49 & Nível superior & Português & 3 \\
\hline P2 & F & 47 & Nível superior & $\begin{array}{c}\text { Arte, Filosofia, } \\
\text { Sociologia }\end{array}$ & 6 \\
\hline P3 & F & 44 & Nível superior & Inglês & 6 \\
\hline P4 & F & 31 & Nível Superior & Espanhol & 5 \\
\hline P5 & M & 55 & Nível superior & História & 5 \\
\hline P6 & M & 62 & Nível superior & Matemática & 6 \\
\hline P7 & F & 50 & Nível superior & Português & 3 \\
\hline P8 & M & 50 & Nível superior & Matemática & 5 \\
\hline P9 & F & 54 & Nível superior & Inglês & 3 \\
\hline P10 & F & 49 & Nível superior & Português & 3 \\
\hline
\end{tabular}

Fonte: Autoria própria

No quadro observa-se que dentre os participantes (10 professores), a maior parte da amostra é do sexo feminino, sendo sete mulheres com faixa etária entre 31 e 54 anos, e três homens com faixa etária entre 50 e 62 anos. Dado esse que se corrobora com os resultados da pesquisa realizada pelo Censo Escolar de 2018, apresentando que na educação básica o quadro de docentes é formado em sua maioria por mulheres, com representação de 79,9\%, sendo a maior parte $53,7 \%$ com 40 anos ou mais de idade; e quanto em relação à escolaridade, 79,9\% dos professores que atuam na educação básica possui nível superior completo, dado que também foi percebido na amostra do estudo, visto que todos os professores possuem nível superior completo (INEP, 2018). O que segundo Ataíde e Nunes (2016) se explica historicamente, tendo em vista que o índice de mulheres como docente vem de uma tradição desde que o ensino passou a ser organizado no Brasil e os homens que até então eram os que ocupavam tal função passaram a ir em busca de profissões com salários melhores, abrindo-se assim as portas para que as mulheres pudessem ter acesso a uma profissão, por meio do magistério; além de culturalmente também está associado a imagem e o papel que a mulher representa na sociedade, com suas características femininas, como cuidado, meiguice, tranquilidade e atenção para com os alunos. 
Toda amostra é composta por docentes formados pela rede de ensino pública, e que ministram as disciplinas de: português (3), matemática (2), inglês (2), espanhol (1), história (1) e sociologia, arte e filosofia (1). Quanto a quantidade de turmas ministradas percebe-se que a maioria das professoras tem entre 3 e 6 turmas e os homens entre 5 à 6 turmas.

Assim os resultados dos dados coletados foram subdivididos em categorias, de acordo com os objetivos específicos, como apresentado a seguir: fatores estressores, estratégias de enfrentamento e implicações no processo de ensino-aprendizagem.

\subsection{Fatores estressores}

Em relação aos dados coletados na amostra quanto à maneira como os docentes se sentem no seu ambiente de trabalho, apontaram que a maioria dos professores percebem o seu ambiente de trabalho tranquilo, tendo em vista que recebem o apoio da direção e coordenação e isso os fortalecem enquanto professores na resolução de problemas e também nos relacionamentos interpessoais.

P7: "É um ambiente tranquilo, calmo. Tem os problemas tem, porque toda escola, todo órgão tem seus problemas, mas que a gente vai conseguindo sanar, solucionar através do diálogo e temos bastante apoio da gestão, então eles estão sempre nos apoiando em qualquer circunstância."

P3: "Eu percebo a escola boa, é que tudo falta muita estrutura no estado, mas eu gosto muito daqui a coordenação, a parte gestora da escola é muito bem estruturada."

O ensino na Educação básica de maneira geral segundo Cabral (2016), é regido e influenciado por vários fatores que permeiam uma educação de qualidade e que visa contribuir para o desenvolvimento da sociedade, como: a quantidade de alunos por turma, os materiais pedagógicos utilizados, a infraestrutura da escola, a metodologia de ensino, laboratórios, e também a valorização dada aos profissionais que compõem o corpo docente; são fatores que unidos, cada um com seu significado e valor compõem o quadro de uma escola pública relevante e adequada para o ensino.

Entretanto percebeu-se que apesar de a escolar ter uma gestão com estrutura de qualidade, existem fatores que dentro do ambiente escolar lhe causam estresse e tornam a profissão professora estressante, como foi apontado pela docente (P10): "Em relação ao convívio com os profissionais eu me dou bem, em relação aos alunos normalmente eu

Educação, Psicologia e Interfaces, Volume 4, Número 2, p. 135-149, Abril/Junho, 2020. 
não tenho problema nenhum, mas no geral a profissão professora é estressante." Percebeu-se assim, por meio das falas que os professores se sentem acolhidos pela escola, gostam do alunado, dos colegas de trabalho e apesar de ser uma escola da periferia, não existe histórico de brigas e discussões, o que permite eles caracterizarem o seu ambiente de trabalho como calmo, pela maioria dos participantes. Para Meleiro (2002) ser professor é uma profissão louvável, entretanto devido as constantes deteriorações, principalmente falta de respeito, reconhecimento, estrutura física e de material, a mesma se tornou uma das profissões mais estressantes da atualidade.

Assim, quanto aos fatores causadores de estresse os docentes referiram que envolve principalmente a estrutura física da escola, tendo a falta de ar-condicionado e a superlotação das salas como principais fatores causadores de estresse, sendo apontado por 6 de 10 entrevistados. P4: "A estrutura em si não é muito boa, quantidade de alunos imensa, salas superlotadas, calor imenso, falta de ar-condicionado." Isso se explica devido as turmas possuírem cerca de 40 alunos, serem pequenas e a cidade de TeresinaPI em que a escola se encontra possuir um clima-semiárido a maior parte do ano, sendo considerada assim, uma das capitais mais quentes do país. Por conta disso, os professores se sentem incomodados com a alta temperatura, quase $40^{\circ}$, e acabam apresentando dificuldades para conseguirem dá aula e controlar os alunos para que os mesmos se concentrem, devido ao forte índice de calor.

Como fatores emocionais foram apontados a indisciplina dos alunos (barulho, conversas fora de hora, xingamentos, falta de respeito com os colegas e professores), a falta de compromisso dos mesmos com as disciplinas e a falta de responsabilidade dos pais com os filhos frente a demandas escolares e familiares, respectivamente como segue nas falas: "Indisciplina e quando o aluno é grosseiro." (P10); "Falta de respeito dos alunos com professores, e entre eles também, deles se xingando, brincadeiras fora de hora entre eles." (P4)"; "Falta de comprometimento dos alunos com línguas estrangeiras, porque eles têm elas como descartáveis." (P3); “Comportamento de alguns pais, em tornar a escola responsável por problemáticas que não é nosso. Tipo a automutilação de alunos. Aí o comodismo e esquivas das famílias em procurar ajuda para os filhos, me deixa muito estressada." (P2).

Percebe-se que os professores passam por diversos estressores, que estão diariamente os acompanhando e que perpassam as mais diversas ordens, como descrito 
pelas falas acima, fazendo com que se sintam desvalorizados, desrespeitados e muitas vezes culpabilizados, por não darem conta de abarcar todas as funções que lhe são impostas e que extrapolam a mediação do processo de conhecimento do aluno e ampliase a missão do profissional para além da sala de aula, a fim de garantir uma articulação entre a escola e a comunidade. Diante de tais acontecimentos, Gasparini et al (2005) pontuam que essas condições de trabalho, nas quais os professores usam de todas as suas capacidades físicas, cognitivas e afetivas para atingir os objetivos da produção escolar podem acabar gerando um grande esforço de suas funções psicofisiológicas.

Assim, como foi apontado por Aliate e Abacar (2018) em seus estudos, o estresse ocupacional é causado por um agente do ambiente de trabalho do qual o sujeito está inserido, ou seja, quando acontece pelo ambiente ou pelas atividades que são destinadas ao sujeito realizar. Percebeu-se assim, que os fatores de maior incômodo e causadores de estresses relatados no estudo, são de acordo com Bittencourt et al (2010), classificados como fatores primários e fatores secundários, tendo o fator primário os aspectos que refletem na atuação do professor em sala de aula, ou seja, os fatores emocionais que foram apresentados e o fator secundário relacionado ao contexto no qual o professor está inserido, que foram as questões físicas.

Dessa forma, é notável a diversidade dos fatores que se apresentam muitas vezes juntos e interferem no bem-estar do organismo, desestabilizando-o e refletindo de forma direta em sua atuação em sala de aula afetando o trabalho do professor que mesmo nesse ambiente aversivo no qual está inserido deve procurar a cautela para a tarefa de ensinar, transmitir valores e impulsionar a sociedade de um modo geral para o futuro (BAIÃO; CUNHA, 2013; WEBER; VEGANI, 2010).

\subsection{Estratégias de enfrentamento}

O processo de adoecimento do educador ocorre, como já apresentado, por meio de estressores relacionados principalmente ao contexto escolar e como apresentam Baião e Cunha (2013), pelo modo como estes são enfrentados, levando em consideração que cada indivíduo responde a um agente estressor de modo diferente, dependendo de sua capacidade psicológica, física e intelectual. Para reduzir os agentes estressantes é necessário ter uma compreensão de si, da sua essência e dos seus mecanismos procurando aumentar a resistência ao estresse e melhorando assim, a saúde (SANTOS; VIDAL,

Educação, Psicologia e Interfaces, Volume 4, Número 2, p. 135-149, Abril/Junho, 2020. 
Estratégias de enfrentamento utilizadas por professores do ensino médio em situação de estresse

2017). Tais estratégias de enfrentamento ou coping são definidas por Lazarus e Folkman (1984 apud MAZON et al. 2008, p. 58) como:

Os esforços cognitivos e comportamentais constantemente alteráveis para controlar, vencer, tolerar ou reduzir as demandas internas ou externas específicas que são avaliadas como excedendo ou fatigando os recursos da pessoa. A forma como a pessoa lida com as situações estressantes desempenha um importante papel na relação entre $o$ estresse e o processo de saúde-doença.

Essas estratégias de enfrentamento classificam-se conforme sua função, focado na emoção ou no problema. O coping de acordo com Lazarus e Folkman (1984 apud DIAS; RIBEIRO, 2019), focalizado na emoção tem o objetivo de alterar o estado emocional da pessoa procurando diminuir ou regular a sensação desagradável causada pelo estresse, tendo como característica o afastamento, fuga do problema e busca por apoio emocional; já o coping focalizado no problema tem como objetivo alterar o problema existente entre o indivíduo e o ambiente que lhe causa sofrimento, tendo como característica um plano de resolução.

Desse modo, no que tange às estratégias de enfrentamento utilizadas frente a essas situações estressoras, os resultados dessa categoria apontaram que os professores utilizam tanto de estratégias focalizadas no problema, quanto estratégias focalizadas na emoção. Entretanto as estratégias focalizadas no problema foram consistentes em toda a amostra, dentre elas: parar e analisar a situação, falar baixo com os alunos, respirar fundo, dialogar, mudar os alunos de lugar e manter autoridade.

P1: "A que eu mais uso é parar e analisar, nunca agir por impulso porque se agirmos dessa forma podemos causar um problema sério."

P2: "Eu tenho uma forma de falar até certo ponto com calma e isso desarma muita gente. Se eu trato o meu aluno com calma e paciência ele vai me retribuir eu penso que é desse modo, se eu falar gritando, ele vai me retribuir gritando também."

P4: "Respirar fundo e reclamar só umas três vezes, se não parar eu peço que saia da sala."

P5: "A conversa, o diálogo, ajuda. Eu sou professor de história, mas não consigo falar só de história, pergunto sobre a família, os relacionamentos, conhecer melhor o aluno eu acho que você se estressa menos em sala de aula. É não criar barreiras entre você e o aluno."

P6: "Separar os alunos para diminuir o converseiro."

P8: "Conversar e explicar a importância do comprometimento escolar, isso ajuda, lógico não são todos que fazem, mas a maioria eu percebo que passa a fazer."

Educação, Psicologia e Interfaces, Volume 4, Número 2, p. 135-149, Abril/Junho, 2020.

ISSN: 2594-5343. DOI: $10.37444 /$ issn-2594-5343.v4i2.234 
P10: "Em relação ao barulho que fazem eu tomo providências, medidas cabiveis para que eles silenciem, eu converso com a turma, eu como autoridade em sala de aula, eu exijo e mando que se calem, até porque para eu ministrar a aula eu preciso que a turma esteja em silêncio para eu falar."

As estratégias focalizadas na emoção foram descritas tendo sua realização feita fora da sala de aula e colocadas em segundo plano, como por exemplo: rezar antes de entrar na escola, praticar atividades físicas e ouvir música. “Chego na escola eu costumo ficar no carro e faço uma pequena oração, eu peço que meus problemas fiquem lá fora, peço que a tarde seja agradável." (P5); "Fora da sala de aula a musculação me ajuda e ouvir música, então escuto muita música, em casa, no carro, na academia.” (P1). Percebe-se assim, que os professores buscam estratégias centradas no controle da situação, que tenham o efeito mais rápido para diminuir ou sanar o evento estressante, como as estratégias focadas nos problemas. Visto que as mesmas moderam impactos, aumentam os níveis de bem-estar e reduzem o sofrimento psíquico (DIAS; RIBEIRO, 2019).

Lipp (2016), apresenta que algumas vezes não são todas as situações que podem ser mudadas, diante de determinada situação como essa é preciso que o professor busque utilizar seus recursos internos para que possa conseguir se adaptar, mas para isso faz-se necessário um apoio do corpo escolar, ou seja, os outros professores, diretores e profissionais que possam ajudá-lo, e se, caso a situação não consiga ser mudada é importante que os profissionais de saúde seja acionado. Cabe ressaltar que dos 10 professores entrevistados apenas uma já fez terapia e outra as vezes mensalmente faz terapia grupal, os demais relataram que nunca fizeram e apenas uma apontou sentir a necessidade de fazer.

\section{3 Implicações do estresse no processo de ensino-aprendizagem}

Considerando que o estresse está no ambiente escolar, verificou-se também as implicações dele no processo de ensino-aprendizagem. Como retrata Webber e Vegani (2010) é nesse ambiente em que o professor realiza toda sua missão, ensinar. Dados da amostra comprovam que os professores consideram a existência da relação entre o seu trabalho e o estresse, considerando que muitos se sentem cansados da rotina, da quantidade de turmas para dá aula, da falta de estrutura, fazendo com que essa insatisfação gere um efeito negativo a sua saúde e reflita no seu ensino.

Educação, Psicologia e Interfaces, Volume 4, Número 2, p. 135-149, Abril/Junho, 2020. 
P2: "O trabalho quer queira ou não, você vai estar se desgastando fisicamente e mentalmente. O professor tem a questão da leitura, da escrita no quadro, atividades e é toda uma carga que reflete, no final do dia você vai tá cansado mesmo."

P5: "Só quando chega em sala de aula, às vezes você se depara com problemas muitos pessoais dos alunos, aqui já tivemos problemas de alunos com depressão, problemas em casa e isso ele traz pra sala de aula e você às vezes absorve o problema do aluno e isso leva ao estresse. A uma relação muito grande entre o estresse do professor e o comportamento do aluno."

O estresse do professor impacta na saúde e na vida social do docente, além de refletir de modo negativo na qualidade do processo de ensino e aprendizagem ofertado ao alunado, visto que o trabalho docente associado a um estilo de vida ineficaz pode desencadear o adoecimento e isso acarreta em faltas dos professores, que muitas vezes pode não ter alguém para substituí-lo (BAIÃO; CUNHA, 2013; BENEVIDES, 2011).

Assim, segundo Weber e Vegani (2010), o desgaste causado pelo estresse acarretam em sintomas físicos, como danos aos órgãos digestivos e sistema circulatório que prejudicam não apenas as atividades escolares, mas o desempenho e as atividades diárias do indivíduo o que gera desconforto, cansaço, sensação de medo, raiva, derrota, ansiedade, diminui seu ritmo e capacidade de manter sua vida equilibrada e saudável, tendo como uma consequência muito preocupante para alguém que está em contato com pessoas, o isolamento social, por conta da irritação e falta de paciência com as pessoas (FERREIRA; ZAVODINI, 2006 apud CARNEIRO, 2014).

Tendo em vista tal relação, os dados também mostraram que o professor reconhece que quando está estressado isso se reflete em mal-estar no processo de ensino e influencia no processo de aprendizagem do aluno.

P3: "Interfere muito, professor estressado é um professor sem condição de dar aula. Não vai haver essa relação professor-aluno, alunoprofessor, você vai criar uma barreira tão grande entre você e o aluno que vai ser difícil controlar."

P4: “(...) o ensino é seriamente comprometido pelo professor não está bem fisicamente quanto psicologicamente principalmente.'

P6: "O professor estressado dentro da sala de aula, ele não dá uma boa aula e ele gera no alunado dele um estresse também e aí fica dois estressados dentro da sala de aula e não sai nada. O assunto não flui." P9: "Eu acho que quando o professor tá com o grau de estresse muito grande as vezes ele chega a ser ríspido com o aluno e aí o aluno começa a reclamar, a não querer tá naquela aula, a não gosta da aula, sempre ser do contra em qualquer proposta, recusa, não quer fazer, embora depois

Educação, Psicologia e Interfaces, Volume 4, Número 2, p. 135-149, Abril/Junho, 2020.

ISSN: 2594-5343. DOI: $10.37444 /$ issn-2594-5343.v4i2.234 
ele ceda, então prejudica isso. Porque o aluno começa a sentir até uma rejeição pela matéria."

P10: "Pode influenciar da seguinte forma: Se eu estiver muito estressada eu muitas vezes, sento, fico ali esperando a situação melhorar e aquilo demanda um certo tempo, a gente perde um certo tempo até as coisas se ajustarem e isso aí reflete lá no conteúdo, o tempo foi passando. Tempo perdido é conteúdo perdido. Então acho que vai influenciar dessa maneira, na perda de conteúdo.”

Como abordado por Benevides (2011), o professor com adoecimento muitas vezes pode apresentar atos de desumanização, passando a ter um contato distante dos alunos, agindo de maneira agressiva, gerando uma perda nos relacionamentos interpessoais entre professor-aluno e aluno-professor, além também de refletir na transmissão do conteúdo que acaba sendo prejudicado, levando assim a uma perda no processo de aprendizagem dos discentes. Diante disso, conclui-se o quanto um fator desencadeador de estresse pode ser prejudicial à saúde de um profissional frente ao seu papel enquanto educador.

\section{CONSIDERAÇÕES FINAIS}

Portanto, tendo em vista os aspectos mencionados, pode-se concluir que os fatores estressores envolvem principalmente a estrutura física da escola, como a falta de arcondicionado e superlotação das salas; e fatores emocionais como a indisciplina dos alunos (barulho, conversas fora de hora, xingamentos, falta de respeito com os colegas e professores), a falta de compromisso dos mesmos com as disciplinas e a falta de responsabilidade dos pais com os filhos frente às demandas escolares e familiares. Assim, as estratégias de enfrentamento utilizadas diante desse contexto foram as focalizadas no problema como: parar e analisar a situação, falar baixo com os alunos, respirar fundo, dialogar, mudar os alunos de lugar e manter autoridade dentro da sala de aula e as focalizadas na emoção como: rezar, fazer exercícios físicos e ouvir música.

Dessa forma a pesquisa alcançou os seus objetivos de estudo estabelecidos, considerando que foi capaz de estabelecer os fatores causadores de estresse, as estratégias de enfrentamento usadas pelos professores diante desses fatores, além de também apontar a implicação do estresse no processo de ensino e aprendizagem.

Diante do exposto, destaca-se que o estudo trata-se de um grupo específico, assim, seus dados não podem ser generalizados, entretanto sugere-se a realização de mais estudos com direcionamento às estratégias de enfrentamento com o intuito de ampliar as

Educação, Psicologia e Interfaces, Volume 4, Número 2, p. 135-149, Abril/Junho, 2020. 
possibilidades de intervenção e prevenção, além de buscar entender a situação em que os professores de escolas públicas estão inseridos e as condições que passam diariamente para realizarem seu trabalho.

Assim, diante desse contexto no qual o professor está inserido é importante pensar em uma educação com políticas públicas de prevenção de saúde com o olhar voltado para esses profissionais, buscando promover estrutura física e materiais de qualidade, além de intervenções que facilitem os laços interpessoais, não somente entre aluno e professor, mas também entre os profissionais, familiares e comunidade, , refletindo em saúde física e mental, para que possam realizar seu trabalho de forma produtiva e satisfatória, resultando assim em um ensino eficaz.

\section{REFERÊNCIAS BIBLIOGRÁFICAS}

ALIANTE, Gildo; ABACAR, Musssa. Fontes de Stress Ocupacional em Professores do Ensino Básico e Médio em Moçambique, Brasil e Portugal: uma Revisão Sistemática de Literatura. Revista Internacional Em Língua Portuguesa, (33), 95-110. Doi: https://doi.org/10.31492/2184-2043.RILP2018.33/pp.95-110

ATAIDE, Patrícia Costa. NUNES, Iran de Maria Leitão. Feminização da Profissão Docente: as representações das professoras sobre a relação entre ser mulher e ser professora do ensino fundamental. Revista Educação e Emancipação, São Luís, v. 9, n. 1, jan./jun. 2016

BAIÃO, L. P. M.; CUNHA, R.G., Doenças e/ou disfunções ocupacionais no meio docente: uma revisão de literatura. Revista Formação Docente, Belo Horizonte vol. 5, n 1, jan/jun 2013.

BALDIN, Nelma; MUNHOZ, Elzira M. Bagatin. Snowball (de Neve): uma técnica metodológica para pesquisa em educação ambiental comunitária. X Congresso de Educação-Educere. Curitiba, 2011.

BARDIN, Laurence. Análise de Conteúdo. Tradução Luís Antero Reto, Augusto Pinheiro. São Paulo: Edições 70, 2016.

BENEVIDES-PEREIRA, Ana Maria Teresa. O burnout docente e seu reflexo no ensino. X Congresso Nacional da Educação-EDUCERE, 2011.

BITTENCOURT, Maria das Graças S. Q.; BELLADELLI, Ediana Maria Noatto; SOMACAL, Cristiane Maccari. O estresse do professor no ensino fundamental. II Simpósio Nacional de Educação, 2010.

BRASIL. Ministério da Educação. Inep. Censo Escolar 2018. Brasília, 2018. Disponível em: portal.inep.gov.br Acesso em: 12 de janeiro de 2020.

Educação, Psicologia e Interfaces, Volume 4, Número 2, p. 135-149, Abril/Junho, 2020.

ISSN: 2594-5343. DOI: $10.37444 /$ issn-2594-5343.v4i2.234 
CARNEIRO, Stania Nagila Vasconcelo. O nível de estresse do professor do ensino fundamental em escolas em Canindé - Ceará. Revista de Educação e Ensino. Ano XVI. Número 19, Jan./Jun. 2014.

CABRAL, Enadir da Silva. O trabalho docente no ensino médio no estado de Santa Catarina: Embates, desafios e possibilidades à valorização dos professores. Dissertação (Mestrado)-Universidade do Sul de Santa Catarina, Tubarão, 2016.

DIAS, Ewerton Naves; RIBEIRO, José Luís Pais. O Modelo de Coping de Folkman e Lazarus: Aspectos Históricos e Conceituais. Revista Psicologia e Saúde, v. 11, n. 2, maio/ago. p. 55-66, 2019.

GASPARINI, M. S.; BARRETO, S.M; ADA, A.A. O professor, as condições de trabalho e os efeitos sobre sua saúde. Rev. Educação e Pesquisa, São Paulo, v. 31, n. 2, p. 189-199, Maio/Ago. 2005

GERHARDT, T. E; SILVEIRA, D. T. (Org). Métodos de Pesquisa. 1 ed. Porto Alegre: Editora da UFRGS, 2009.

GIL, Antônio Carlos. Como elaborar projetos de pesquisa. 4. ed. - São Paulo: Atlas, 2002.

Instituto de Psicologia e Controle do Stress. Pesquisa: stress Brasil. 2013. Disponível em www.estresse.com.br: http://www.estresse.com.br/pesquisa/stress-brasil/ Acesso em 05 de maio de 2019.

KRAWCZYK, Nora. Reflexão sobre alguns desafios do ensino médio no brasil hoje. Cadernos de pesquisa, v.41 n.144 set./dez. 2011

LIPP, M. N. O. Stress do professor frente ao mau comportamento do aluno. In: FAVA, D. C.A Prática da Psicologia na Escola. BH: Ed. Artesã, 2016

MAZON, Vânia; CARLOTTO, Mary Sandra; CÂMARA, Sheila. Síndrome de Burnout e estratégias de enfrentamento em professores. Arquivos Brasileiros de Psicologia, v. 60, n. 1, 2008.

MELEIRO, A. M.A.S. O stress do professor. In: LIPP. M.N. O stress do professor. $5^{\circ}$ edição. Campinas, SP: Papirus, 2007.

MINAYO, M. C. S (org.). Pesquisa Social. Teoria, método e criatividade. $21^{\circ} \mathrm{ed}$. Petrópolis: Vozes, 2002.

Organização das Nações Unidas. Estresse, doenças e longas jornadas contribuem para 2,8 milhões de mortes por ano, indica OIT. (s.d.). Disponível em nacoesunidas.org: https://nacoesunidas.org/estresse-doencas-e-longas-jornadascontribuem-para-28-milhoes-de-mortes-por-ano-indica-oit/ Acesso em 06 de maio de 2019 
SANTOS, L.A.M.; VIDAL, V.M. O estresse do professor: estudo acerca da corporeidade em profissionais da educação básica. Revista Eletrônica de Geografia e Interdisciplinaridade -Interespaço. V.3, n.11, dez. 2017

TOSTES, M. V e et al. Sofrimento mental de professores do ensino público. Saúde debate. Rio de Janeiro, v. 42, n. 116, p. 87-99, jan-mar 2018.

WEBER, D. V., VERGANI, V. A profissão de professor na sociedade de risco e a urgência por descanso, dinheiro e respeito no meio ambiente laboral. XIX Encontro Nacional do CONPEDI. Fortaleza - CE, Junho, 2010.

\section{Credenciais da/os autora/es}

LUCENA, Hiolly Cristina - Graduanda do Curso de Graduação em Psicologia da Universidade Estadual do Piauí (UESPI). E-mail: hiollyclucena@gmail.com

FREITAS, Camila Siqueira Cronemberger - Professora do Curso de Psicologia da Universidade Estadual do Piauí (UESPI). Doutoranda e Mestra em Educação, com área de pesquisa em Educação Especial e Inclusiva, pela Universidade Federal do Piauí. Email: camilasiqueirapsi@gmail.com

Endereço para correspondência: Camila Siqueira Cronemberger Freitas. E-mail: camilasiqueirapsi@gmail.com

Como citar este artigo (Formato ABNT): LUCENA, Hiolly Cristina; FREITAS, Camila Siqueira Cronemberger. Estratégias de enfrentamento utilizadas por professores do ensino médio em situação de estresse. Educação, Psicologia e Interfaces, v. 4, n.2, p. 135-149, 2020. Doi: 10.37444/issn-2594-5343.v4i2.234

Recebido: 07/02/2020.

Aceito: 20/03/2020. 